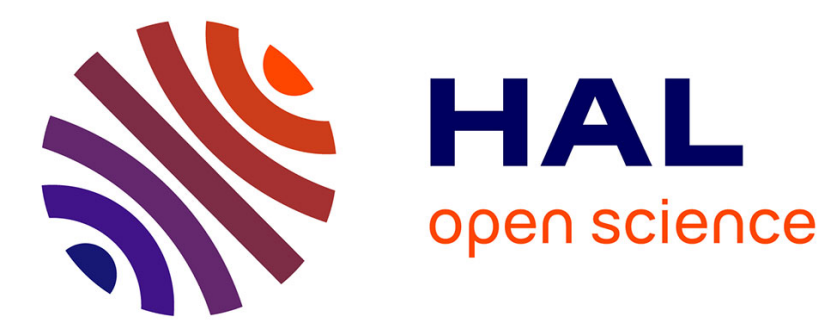

\title{
Hindered rotational barriers in conjugated donor-acceptor substituted systems: calculations vs. experiments
}

Mark Sigalov, Vladimir Lokshin, Nina Larina, Vladimir Khodorkovsky

\section{- To cite this version:}

Mark Sigalov, Vladimir Lokshin, Nina Larina, Vladimir Khodorkovsky. Hindered rotational barriers in conjugated donor-acceptor substituted systems: calculations vs. experiments. Physical Chemistry Chemical Physics, 2020, 22 (3), pp.1214-1221. 10.1039/c9cp06234c . hal-02909943

\section{HAL Id: hal-02909943 \\ https://hal.science/hal-02909943}

Submitted on 27 Nov 2020

HAL is a multi-disciplinary open access archive for the deposit and dissemination of scientific research documents, whether they are published or not. The documents may come from teaching and research institutions in France or abroad, or from public or private research centers.
L'archive ouverte pluridisciplinaire HAL, est destinée au dépôt et à la diffusion de documents scientifiques de niveau recherche, publiés ou non, émanant des établissements d'enseignement et de recherche français ou étrangers, des laboratoires publics ou privés. 


\section{Hindered rotational barriers in conjugated donor - acceptor substituted systems: calculations vs. experiments}

Received 00th January 20xx, Accepted 00th January 20xx

DOI: $10.1039 / x 0 \times x 00000 x$

\begin{abstract}
Mark Sigalov, ${ }^{\mathrm{a}}$ Vladimir Lokshin, ${ }^{\mathrm{b}}$ Nina Larina, ${ }^{\mathrm{b} \dagger}$ and Vladimir Khodorkovsky*,b
Quantum mechanical calculations of barriers to rotation within push-pull $\pi$-conjugated molecules involving strong electron donors (D) and acceptors (A) using the generally accepted approach fail to reproduce the experimental barriers determined by temperature-dependent NMR spectra. On the examples of seven derivatives of this type with substituents of varying electron donating and accepting strength, we find that determination of one of the rotational barriers, for instance, that of the acceptor substituent, requires not only the energy calculation of the respective transition state of this substituent, but also the transition state of the donor and the transition state involving both donor and acceptor substituents. Calculations of the rotation barriers using B3LYP and APFD functionals considering three transition states produce the results with mean absolute deviations from experimental 10 barriers of $0.28-0.19 \mathrm{kcal} / \mathrm{mol}$ depending on the basis set.
\end{abstract}

\section{Introduction}

Conjugated electron donor - acceptor substituted molecules, also known as push-pull $\pi$-conjugated molecules, represent an important class of organic compounds owing to the intramolecular through-bond charge transfer phenomenon giving rise to a variety of specific and practically useful properties. Thus, these derivatives are used as synthetic dyes

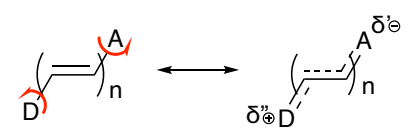

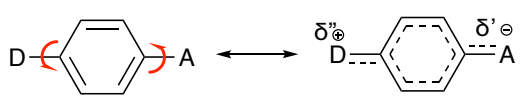

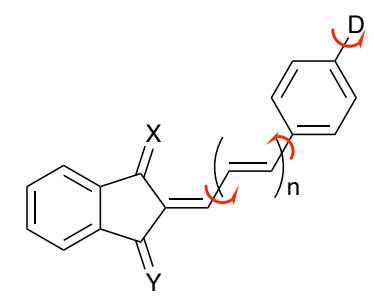

IDX, $\mathrm{X}, \mathrm{Y}=\mathrm{O}, \mathrm{C}(\mathrm{CN})_{2}, \mathrm{n}=0-2$

Scheme 1. Chemical structures of the push-pull derivatives with rotating electron donating $D$ and accepting $A$ substituents.

a. Dept. of Chemistry, Ben-Gurion Univ. of the Negev, Beer-Sheva, 84105, Israel b. Aix Marseille Université, CNRS, CINaM UMR 7325, 13288, Marseille, France. Email: khodor@cinam.univ-mrs.fr

+ Present address: Thales DIS France SA, Avenue du Pic de Bertagne, 13420 Gèmenos, France.

Electronic Supplementary Information (ESI) available: Full tables of computational results and statistical comparison of different calculation methods. See DOI: $10.1039 / x 0 x \times 00000 x$ with light absorption in visible and NIR ranges, as active components of photochromic materials, nonlinear absorbing materials, organic light emitting diodes, sensors, and many other applications. ${ }^{1}$

The properties of push-pull $\pi$-conjugated molecules depend on the electron donor (D), electron acceptor $(A)$ strength and the ability of the conjugating bridge to participate in intramolecular charge transfer, in other words, on the contribution of the charge-separated mesomeric form into the electronic structure of such molecules, as shown in Scheme 1 for polyene systems and those involving an aromatic ring. Enhanced interaction between the $D$ and $A$ moieties gives rise to increasing molecular dipole moments, red shifts of the longest wavelength absorption band and, in particular, progressively shortening the D-bridge and A-bridge bonds. Indeed, if the D - A interaction is weak or not existent, the bonds D-bridge and A-bridge are essentially single and, in the absence of steric hindrance, allow almost unrestricted rotation of both the $D$ and $A$ moieties with respect to the molecular plane. In this case the molecular properties are mostly defined by the neutral mesomeric form, which contribution is close to unity. The increasing $D-$ bridge A interaction hinders the rotation and, in the case of considerable charge transfer, the contribution of the chargeseparated mesomeric form is predominant, the barriers to rotation over the double bonds are high. The degree of charge transfer $\delta^{\prime}$ toward the A moiety from the bridge and the $D$ moiety is, in general, is not the same as the degree of charge transfer $\delta^{\prime \prime}$ from the D moiety. The both deltas depend on the properties of D, A and the bridge, the latter compensates the charge difference between $\delta^{\prime}$ and $\delta^{\prime \prime}$. The influence of the rotating and frozen $D$ and $A$ moieties on the NMR signal shapes is considerable and this feature makes variable-temperature (dynamic NMR, D-NMR) technique indispensable for determining the rotation barriers of the both $D$ and $A$ moieties 
in the range of about $4.5-23 \mathrm{kcal} / \mathrm{mol}$, owing to the limitations of the S-NMR technique. ${ }^{2}$

To date, the barriers to internal rotation about the single bonds possessing partial double bond character $\left(\Delta G^{\neq}\right.$, activation barriers extrapolated to room temperature, $\Delta G^{*}{ }_{c}$, barriers at the coalescence temperature) have been determined using D-NMR with the precision of $0.15-0.5 \mathrm{kcal} / \mathrm{mol}$ for several organic compounds. ${ }^{2,3,4}$ A general notion is that the Density Functional Theory (DFT) based calculations reproduce the experimental barriers to rotation reasonably well ${ }^{4}$ and the calculation of the barrier to rotation of the acetyl group in $p$ dimethylaminoacetophenone is provided as one of the exercises in the last edition of the Gaussian software tutorial. ${ }^{5}$ However, in spite of the abundance of the experimental data on the barriers to rotation of the push-pull molecules, ${ }^{2-4,6}$ the calculations on these derivatives are mostly limited by relatively weak $D$ and A couples ( $p$-methoxy-and $p$-aminoacetophenones and benzaldehydes $)^{7,8}$ and more complex tetrasubstituted push-pull ethylenes, for which the barrier to rotation was calculated for the elongated owing to the push-pull effect ethylene double bonds. ${ }^{9,10}$ To the best of our knowledge, no systematic studies in this important field have been undertaken. During our initial attempts to design new efficient chromophores for electro-optical applications, we used a series of known model compounds involving the 1,3-indandione accepting moiety (IDX in Scheme 1) $)^{11,12}$ and both ethylene and $p$-phenylene bridges, to determine the barriers to rotation using the D-NMR techniques. Photochromic conversions of a number of the IDX-type molecules ${ }^{13,14}$ also involve rotation over the partially double bonds, and correct estimation of the rotational barriers is important for designing effective photo-switchable molecules. The respective calculations using different DFT methods yielded, however, quite confusing results: the computed barriers for a number of derivatives severely overestimated the experimental values by about $1-3 \mathrm{kcal} / \mathrm{mol}$ and sometimes underestimated them by more than $1 \mathrm{kcal} / \mathrm{mol}$. Whereas revealing a systematic trend in the deviation of the computed values from the experimental ones would be also acceptable, we failed to find any correlation between the derivative structures and the computational results and,
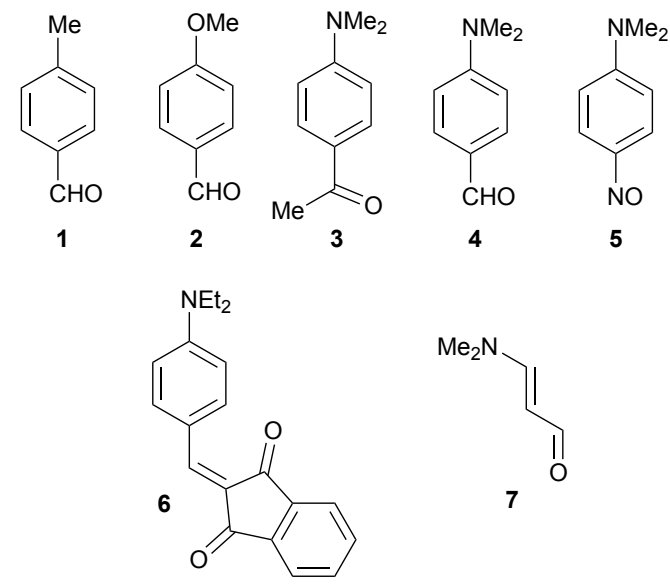

Scheme 2. Molecular structures of derivatives under investigation therefore, the utility of predictions on the properties of yet unknown compounds was doubtful.

Here we present our experimental and computational results on a series of simple push-pull derivatives $\mathbf{1 - 7}$ (Shceme 2) and propose an alternative approach for calculating the rotational barriers.

\section{Experimental}

All calculations were carried out using Gaussian 16 software. ${ }^{15}$ Geometry optimizations of the stationary structures were done using tight conversion criteria and Gaussian 16 defaults (in particular, integral=ultrafine). The relaxed potential energy surfaces (PES) for derivatives $\mathbf{3}$ and $\mathbf{4}$ were calculated by rotating the $\mathrm{D}$ and $\mathrm{A}$ substituents independently by $180^{\circ}$, step $5^{\circ}$ (for 3) and $90^{\circ}$, step $10^{\circ}$ (for 4) from the pre-optimized ground states for both molecules using opt=(modredundant, tight) keyword. The dihedral angle for rotating the dimethylamino group of $\mathbf{4}$ was determined as the angle between the two methyl groups and $\mathrm{C} 3$ and $\mathrm{C} 5$ carbon atoms of the benzene ring to avoid discontinuity of the surface. There was no difference in total electronic energies of the ground (GS) and transition states (TS) calculated for derivative $\mathbf{3}$ found by PES and calculated by Berny algorithm, this difference did not exceed $0.09 \mathrm{kcal} / \mathrm{mol}$ for 4 .

The transition state (TS) geometries and energies used for the barrier calculations were found using Berny algorithm. Harmonic frequency calculations at the same level verified achieving ground states (GS) (zero imaginary frequencies) and TS (one or two imaginary frequencies) and provided the estimates of the free energies G. All calculations were performed using the default self-consistent reaction field (SCRF) model. The highest barriers were selected in the cases when rotation of the substituents over $360^{\circ}$ was found to involve two different minima or maxima for GS and TS (like in the case of syn- and anti- conformers of $p$-methoxybenzaldehyde 2). We used MP2, DFT (B3LYP16, APFD ${ }^{17}$ and $M 062 X^{18}$ ) and hybrid B2PLYPD ${ }^{19}$ theoretical levels with $6-311+G(2 d, p)$, 6$311++G(2 d f, 2 p)$, aug-cc-pVDZ and aug-cc-pVTZ basis sets.

\section{Variable temperature ${ }^{1} \mathrm{H}$ NMR spectra}

Derivatives $\mathbf{5}$ and $\mathbf{7}$ were obtained from TCl Europe. Derivative 6 was prepared according to ref. ${ }^{20}$ Variable temperature ${ }^{1} \mathrm{H}$ NMR spectra were recorded on the Bruker AMX-400 spectrometer at $400.1 \mathrm{MHz}$, in $\mathrm{CD}_{2} \mathrm{Cl}_{2}$ and toluene-d8 in the temperature range $190-300 \mathrm{~K}$ for compounds $\mathbf{5}$ and $\mathbf{6}$, and 280 $320 \mathrm{~K}$ for compound 7 . The barriers to rotation were measured as the energy of activation at the coalescence temperature $\left(T_{c}\right)$ for aromatic protons (derivatives $\mathbf{5}$ and $\mathbf{6}$ ), and methyl groups (derivatives $\mathbf{5}$ and $\mathbf{7}$ ). The rate constants of exchange $K_{c}$ were obtained from equation:

$\mathrm{K}_{\mathrm{c}}=\pi \Delta \mathrm{v} / \mathrm{V} 2$

and the barriers to rotation at the coalescence temperature $T_{c}$ by substitution of the $\mathrm{K}_{\mathrm{c}}$ values into modified Eyring equation ${ }^{3}$ : $\Delta \mathrm{G}^{\neq}=4.57 \mathrm{~T}_{\mathrm{c}}\left\{9.97+\log \left(\mathrm{T}_{\mathrm{c}} / \Delta \mathrm{v}\right)\right\}$. 


\section{Results and discussion}

The series of push-pull derivatives $\mathbf{1}-\mathbf{7}$, selected for calculations, involves $p$-substituted benzenes $\mathbf{1}-\mathbf{5}$, for which the data on the barriers to rotation are available from the published results. Derivative $\mathbf{6}$ is a parent compound for the IDX-type series of push-pull derivatives. Derivative $\mathbf{7}$ is a simplest push-pull conjugated molecule involving the same electron acceptor $(\mathrm{HC}(\mathrm{O})-)$ and donor $\left(\mathrm{Me}_{2} \mathrm{~N}-\right)$ as 4 , but linked by the ethene bridge. The calculations of the barriers to rotation over the C-A and C-D bonds (denoted further as $B_{A}$ and $B_{D}$ ) were carried out in the same solvent used in D-NMR experiments, except those for derivative $\mathbf{1}$ and $B_{D}$ barriers for derivatives 3 and $\mathbf{4}$, for which toluene was used as the solvent. The frequency jobs were done at the coalescence or room temperatures, when the latter were available (Table 1). For comparison with the calculated values, we selected the available experimental data, while avoiding, wherever possible, those obtained in the solvent mixtures and polar solvents that can interact with the solute specifically. We also carried out the experiments on derivatives 5 - 7 to perform the full line shape analysis. In addition, the considerable degree of charge transfer in both $\mathbf{5}$ and, especially, 7 can make these compound more sensitive to the solvent polarity. The two available experimental barrier $B_{D}$ values for 7 $\left(\Delta \mathrm{G}^{{ }_{\mathrm{c}}}=14.68 \mathrm{kcal} / \mathrm{mol}\right.$ at $291.9 \mathrm{~K}^{21}$ in 1,1-dichloroethylene and $15.6 \mathrm{kcal} / \mathrm{mol}$ at $305 \mathrm{~K}^{22}$ in dibromomethane) confirm that the difference in barriers in different solvents can be considerable.

Table 1. Experimental barriers to rotation over the C-A and C-D bonds and conditions for derivatives $1-7$

\begin{tabular}{|c|c|c|c|c|}
\hline Comp & $\begin{array}{l}\Delta \mathrm{G}^{\neq} \\
(\mathrm{kcal} / \mathrm{mol})\end{array}$ & Temp (K) & Solvent & Ref. \\
\hline 1 & 8.5 & $165.5^{a}$ & $\begin{array}{l}\mathrm{CH}_{2} \mathrm{Cl}_{2} / \\
\mathrm{CH}_{2}=\mathrm{CHCl}\end{array}$ & 23 \\
\hline 2 & 9.4 & $198^{a}$ & toluene $_{\mathrm{d} 8}$ & 24 \\
\hline 3 & $\begin{array}{l}8.5 \\
7.2^{b}\end{array}$ & $\begin{array}{l}181^{a} \\
133\end{array}$ & $\begin{array}{l}\text { toluene }_{\mathrm{d} 8} \\
\text { toluene } \mathrm{d} 8 / \\
\mathrm{CH}_{2}=\mathrm{CHCl}\end{array}$ & $\begin{array}{l}24 \\
25\end{array}$ \\
\hline 4 & $\begin{array}{l}10.7 \\
7.8^{b}\end{array}$ & $\begin{array}{l}205-212.5^{a} \\
133\end{array}$ & $\begin{array}{l}\mathrm{CD}_{2} \mathrm{Cl}_{2} \\
\text { toluene } \mathrm{d} 8 / \\
\mathrm{CH}_{2}=\mathrm{CHCl}\end{array}$ & $\begin{array}{l}23,26 \\
25\end{array}$ \\
\hline 5 & $\begin{array}{l}12.3 \\
9.9^{b}\end{array}$ & $\begin{array}{l}298 \\
201^{a}\end{array}$ & $\begin{array}{l}\text { toluene }_{\mathrm{d} 8} \\
\text { toluene }_{\mathrm{d} 8}\end{array}$ & $\begin{array}{l}\text { This } \\
\text { work } \\
\text { - " - }\end{array}$ \\
\hline 6 & 10.2 & 298 & $\mathrm{CD}_{2} \mathrm{Cl}_{2}$ & $-"$ - \\
\hline 7 & $15.0^{b}$ & 298 & toluene $_{\mathrm{d} 8}$ & $-"$ \\
\hline
\end{tabular}

a Coalescence temperature.

b C-D bond.

Our initial calculations of the barriers (B) were done according to the protocol described on the example of derivative $3^{5}$ assuming $\Delta \mathrm{G}^{\neq}=\mathrm{B}=\mathrm{G}_{\mathrm{TS}}-\mathrm{G}_{\mathrm{GS}}$. This approach is referred in the following discussion as the one-state approximation. Thus, it

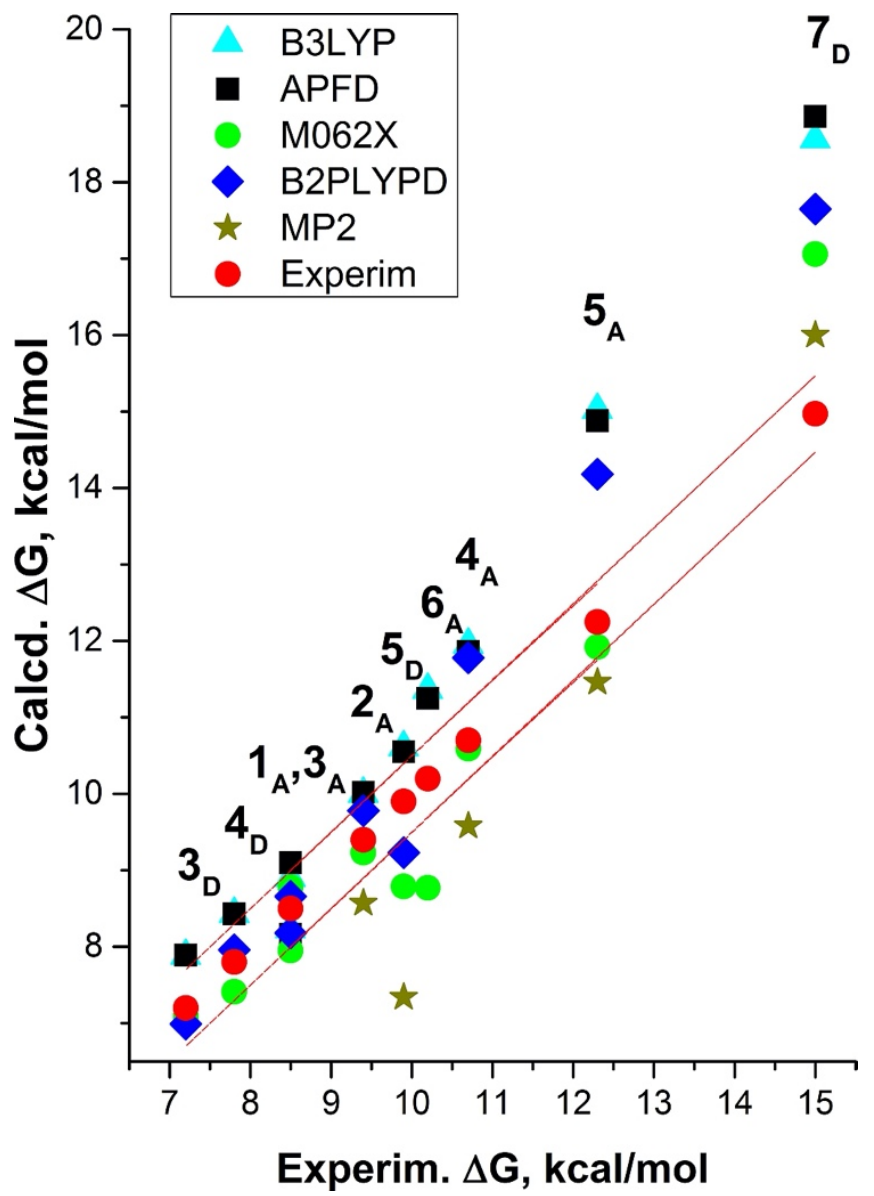

Figure 1. Calculated $\left(6-311++G(2 d f, 2 p)\right.$ basis set) $\Delta G_{A(D)}^{*}=B_{A(D)}=G_{T S}-G_{G S}$ (one-state approximation) vs. experimental $\Delta \mathrm{G}^{*} \mathrm{A(D)}$ (red circles, $+/-0.5 \mathrm{kcal} / \mathrm{mol}$ denoted by dashed red lines).

does not take into account the interaction between already rotating substituent and yet frozen substituent occurring under the experimental conditions of determining the barrier to rotation of the latter. Although in the recent review ${ }^{4}$ it was noted that the barriers computed at the DFT level using the total energies without the ZPE correction provide usually good fit with the experimental $\Delta G^{\ddagger}$ values, we preferred to introduce the thermodynamic corrections and compare the free energies, as the above notion might be not valid in the case of push-pull derivatives. We employed the popular B3LYP functional recommended in ${ }^{4}$, APFD used in book ${ }^{5}$ and M062X functional parametrized to reproduce, in particular, the thermodynamic and kinetic data and frequently used for calculations of the push-pull derivatives ${ }^{8,27-30}$. Although the MP2 and B2PLYPD levels are not practical for computations on larger molecular systems, we also used both for a number of molecules to see if these methods provide better fit with the experiment. 
Quantum mechanical calculations using one-state approximation

For comparison of the computational results with the experimental, we assume that the deviation of $+/-0.5 \mathrm{kcal} / \mathrm{mol}$ is acceptable considering that the experiments were done using different techniques in different laboratories and, in some cases in a mixture of solvents. A summary of the results on derivatives $\mathbf{1 - 7}$ using the $6-311++\mathrm{G}(2 \mathrm{df}, 2 \mathrm{p})$ basis set is presented in Figure 1. Further increase of the basis set did not noticeably change the resulting barrier energies.

The calculated $B_{A}$ and $B_{D}$ values using all methods give satisfactory results only when the experimental $\Delta G^{\neq}$are below $9.5 \mathrm{kcal} / \mathrm{mol}$. For the derivatives with higher experimental barriers, both B3LYP and APFD functionals give similar numbers overestimating the experimental values progressively up to $3-$ $3.5 \mathrm{kcal} / \mathrm{mol}$ for derivative 7 , not depending considerably on the basis set (see Tables $1 S-22 S$ and Figures 1S, 2S, ESI). Similar results were obtained by the hybrid B2PLYPD method, although the overestimation for $\mathbf{7}$ is smaller (about $2.7 \mathrm{kcal} / \mathrm{mol}$, Figure 1 ). A very good fit is observed in the case of the M062X functional for derivatives $\mathbf{1}-\mathbf{4}$ and $\mathbf{5}\left(\mathrm{B}_{\mathrm{A}}\right)$. At the same time, this model chemistry underestimates the barriers for $5\left(B_{D}\right)$ and 6 (by $1.4 \mathrm{kcal} / \mathrm{mol}$ ) and overestimates the barrier for 7 (by 2.1 $\mathrm{kcal} / \mathrm{mol}$ ). For the whole set of compounds, the mean absolute deviations from experiment (MAD) calculated for 10 barriers to rotation (derivatives 1 -7) using B3LYP and APFD do not depend considerably on the basis set and are $0.9-0.8$ and $0.55 \mathrm{kcal} / \mathrm{mol}$ for M062X. MP2 barriers are lower than experimental for all compounds and higher for 7.

The systematic overestimation of the rotational barriers by the well-established methods (B3LYP, APFD and B2PLYPD) indicates that the very approach equating the barrier energy to the difference between the energies of a single transition state and ground states $\left(\Delta \mathrm{G}^{\neq}=\mathrm{G}_{\mathrm{TS}}-\mathrm{G}_{\mathrm{GS}}\right)$ is too simplistic and should not be applied in the cases of strong interaction between the $D$ and A moieties within push-pull conjugated molecules. In our opinion, at least three transition states should be considered for the molecular systems involving two conjugated rotating moieties interacting with each other through the conjugating bridge. These states, $\mathrm{TS}_{\mathrm{A}}, \mathrm{TS}_{\mathrm{D}}$ and $\mathrm{TS}_{\mathrm{DA}}$, are considered within the proposed approach referred further as three-state approximation

\section{Quantum mechanical calculations using three-state approximation}

Let us consider the influence of the rotating moiety over the bond possessing the lowest barrier to rotation on the examples of derivatives $\mathbf{2}$ and $\mathbf{4}$, for which, according to both experiments and calculations, the lowest barriers to rotation correspond to the $D$ group. The calculated barrier energies are schematically presented in Figure 2. Under the condition of rotating $D$ substituents, D-bridge-A conjugation ( $G S->T_{D}$ ) is broken, whereas the $A$ substituent remains conjugated with the bridge. Under the conditions $A$ substituent is rotating, the $D$ substituents are already rotating. Therefore, for $A$ substituent

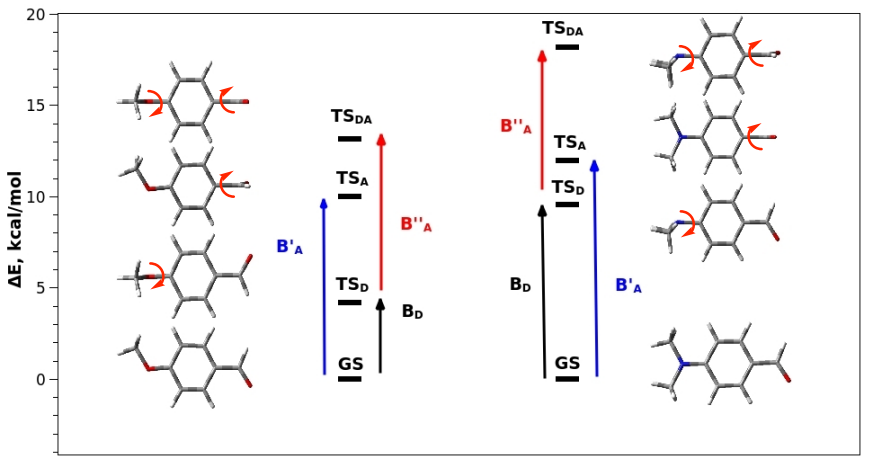

Figure 2. Calculated transition state energies TS and two extreme barriers to rotation $\mathrm{B}_{\mathrm{A}}^{\prime}$ and $\mathrm{B}_{\mathrm{A}}{ }_{\mathrm{C}}$ calculated for $\mathbf{2}$ and $\mathbf{4}$.

there are two extreme cases with regards to the rotating $D$ substituents: at the moment when the $D$ substituents are passing the ground state conformation $\left(\mathrm{GS}->\mathrm{TS}_{\mathrm{A}}\right)$ and at the

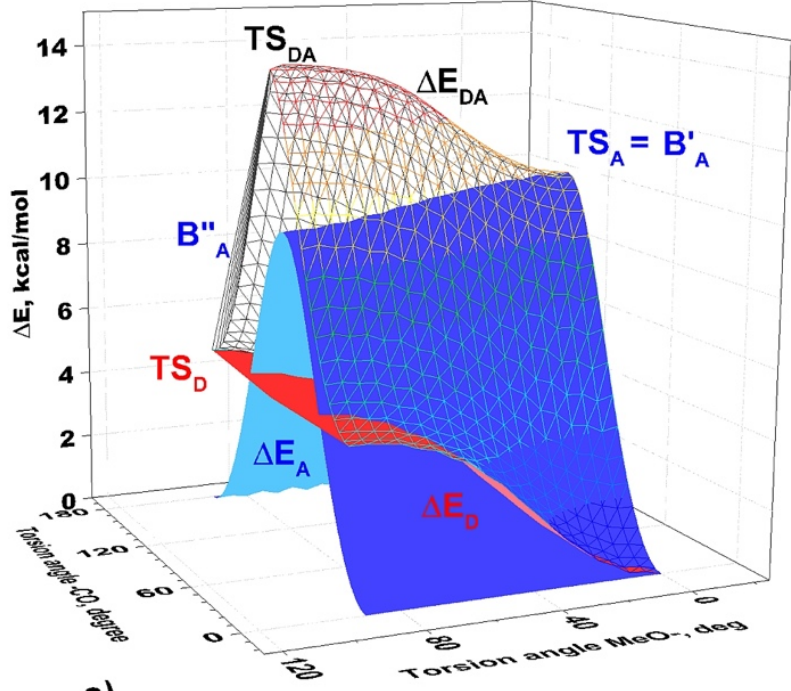

a)

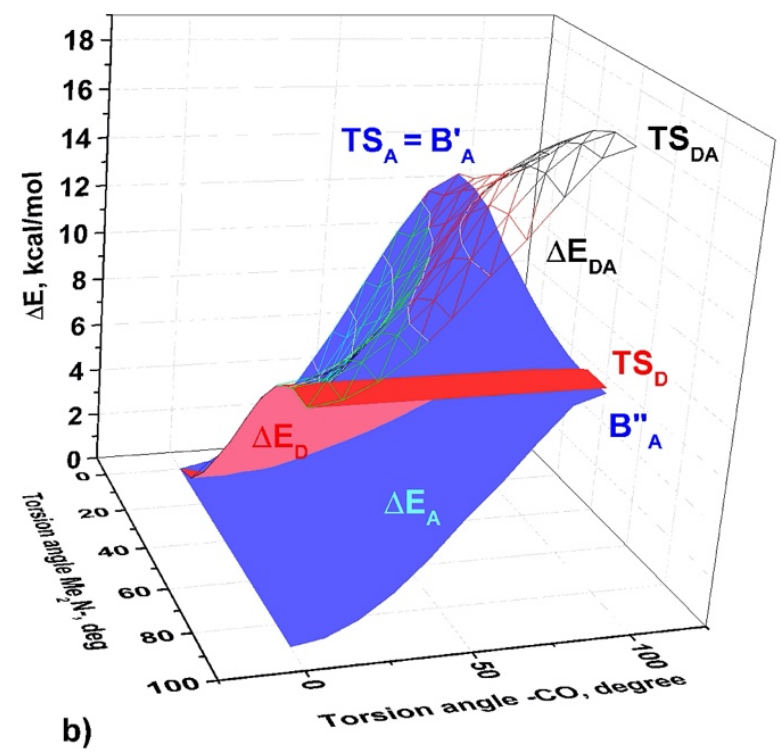

Figure 3. Total relative electronic energy surface $\Delta E_{\text {tot }}$ for derivative $\mathbf{2}$ (a) and $\mathbf{4}$ (b) (mesh surfaces) and their components $\Delta E_{D}$ (red surfaces) and $\Delta E_{A}$ (blue surfaces) (B3LYP/aug-cc-pVDZ model chemistry) 
moment when the dihedral angles between the $D$ substituents and the bridge are close to $90^{\circ}\left(\mathrm{TS}_{\mathrm{D}} \rightarrow \mathrm{TS}_{\mathrm{DA}}\right)$. Obviously, the barriers calculated using the one-state approximation correspond to the GS $->\mathrm{TS}_{\mathrm{A}}$ case, denoted as $\mathrm{B}^{\prime}{ }_{\mathrm{A}}$, and the $\mathrm{TS}_{\mathrm{D}}->$ $\mathrm{TS}_{\mathrm{DA}}$ case, denoted as $\mathrm{B}^{\prime \prime}{ }_{\mathrm{A}}$ in Figure 2 remains completely neglected in the frame of the one-state approximation. The calculated $\mathrm{B}_{\mathrm{A}}{ }_{\mathrm{A}}$ values include thus an overhead: the energy of breaking conjugation of a push-pull molecule, conjugation in which is already broken by rotating $D$ substituent, and the stronger is the conjugation, the larger is the overhead.

The total relative electronic energy scans $\left(\Delta \mathrm{E}_{\text {tot }}\right.$ in $\mathrm{kcal} / \mathrm{mol}, \mathrm{E}_{\mathrm{GS}}=$ 0 ) for $\mathbf{2}$ and $\mathbf{4}$ shown in Figure 3a,b provide more details. Expectedly, the minima on the $\Delta \mathrm{E}_{\text {tot }}$ surfaces for both compounds correspond to the conformation in which the $D$ substituents are conjugated to the $p$-phenylene bridge. These saddle points $\left(\Delta \mathrm{E}_{\text {tot }}=\mathrm{TS}_{\mathrm{A}}\right)$ for $\mathbf{2}$ and $\mathbf{4}$ represent the barriers to rotation traditionally determined in the frame of the one-state approximation (rotation of the $-\mathrm{C}=\mathrm{O}$ group of the chargeseparated mesomeric form). Progressive rotation of $D$ substituents gives rise to the increase in $\Delta \mathrm{E}_{\text {tot }}$ energy and the maxima on the $\Delta \mathrm{E}_{\text {tot }}=\mathrm{TS}_{\mathrm{DA}}$ surfaces correspond to the orthogonal conformation of both $\mathrm{D}$ and $\mathrm{A}$ substituents (rotation of the neutral non-conjugated mesomeric form). Rotation of $D$ substituents while keeping the accepting $-\mathrm{C}=\mathrm{O}$ group conjugated to the bridge, provides the surfaces corresponding to $\Delta \mathrm{E}_{\mathrm{D}}$ (red surfaces) and the difference of $\Delta \mathrm{E}_{\text {tot }}-\Delta \mathrm{E}_{\mathrm{D}}$ presents the variations in $\Delta \mathrm{E}_{\mathrm{A}}$ (blue surfaces). The minima on the $\Delta \mathrm{E}_{\mathrm{A}}$ surfaces coincide with the maxima on the $\Delta \mathrm{E}_{\text {tot }}=\mathrm{TS}_{\mathrm{DA}}$ and $\Delta \mathrm{E}_{\mathrm{D}}=$ $T S_{D}$ surfaces for both derivatives 2 and 4 . The minimum on $\Delta E_{A}$ surface of $\mathbf{4}$ is deeper than $\Delta \mathrm{E}_{\mathrm{A}}$ of $\mathbf{2}$. Further analysis of both surfaces can be simplified by considering the 2-D projections of the surface maxima $\Delta \mathrm{E}_{\text {tot }}$ and $\Delta \mathrm{E}_{\mathrm{A}}$ vs. variation at the rotation angles od $D$ group from $0^{\circ}$ to $90^{\circ}$ (Figure 4 ).

The effect of rotation of the -OMe group ( $D$, the lowest barrier) in derivative $\mathbf{2}$ is as follows: as the dihedral angle of the -OMe group goes from nearly $0^{\circ}$ (conjugated $\mathrm{D}$, as in polar mesomeric form) to $90^{\circ}$ (non-conjugated $D$, as in neutral mesomeric form), the total energy increases from $\mathrm{TS}_{A}$ to $\mathrm{TS}_{\mathrm{DA}}$ (black curve) and the $\mathrm{TS}_{\mathrm{A}}$ barrier decreases from $\mathrm{B}^{\prime}{ }_{\mathrm{A}}$ to $\mathrm{B}^{\prime \prime}{ }_{\mathrm{A}}$, from 10.55 to 9.45 $\mathrm{kcal} / \mathrm{mol}$ (Figure 4a). The experimentally measured barrier to rotation $B_{A}$ should then fall in between these two extremes, with its exact position determined by the relative contributions of each of the two extreme conformations of $D$.

Indeed, assuming $B_{A}=\left(B^{\prime}{ }_{A}+B^{\prime \prime}{ }_{A}\right) / 2$ considerably improves the calculated barriers for the whole set of derivatives. This simple assumption can be refined taking into account that the degree of charge transfer between $D$ and $A$ (Scheme 1 ) can be within the limits of 0 (no charge transfer) and 1 (full charge transfer). Let us designate as $\delta_{A}$ the ratio $\mathrm{TS}_{\mathrm{D}} / \mathrm{TS}_{\mathrm{DA}}$ (in terms of Fig. 2) characterizing the contribution of the polar mesomeric form into the molecular electronic structure (in terms of Scheme 1, full possible charge transfer to $A$ in a conjugated conformation), corresponding to the calculated $A$ rotation barrier $\mathrm{B}^{\prime}{ }_{\mathrm{A}}$. Then the contribution of the non-conjugated form (free rotation, no charge transfer) can be expressed as $\left(1-\delta_{A}\right)$ with the corresponding barrier $\mathrm{B}^{\prime \prime}{ }_{\mathrm{A}}$, and the total barrier value as:
$\mathrm{B}_{\mathrm{A}}=\delta_{\mathrm{A}} \cdot \mathrm{B}_{\mathrm{A}}{ }+\left(1-\delta_{\mathrm{A}}\right) \cdot \mathrm{B}^{\prime \prime}{ }_{\mathrm{A}}$

The calculated $\delta_{A}$ value for derivative $\mathbf{2}$ is 0.33 (using the non ZPE-corrected electronic energies) and, therefore, $B_{A}$ can be calculated as $0.33 \mathrm{~B}_{\mathrm{A}}+0.67 \mathrm{~B}_{\mathrm{A}}=9.81 \mathrm{kcal} / \mathrm{mol}$ (the green horizontal line in Figure 4a). Using the respective values of free energy (Table $4 S, E S I)$, we arrive to $B_{A}=\Delta G^{{ }_{c}}=9.28 \mathrm{kcal} / \mathrm{mol}$ in a good agreement with experiment (Table 1). It is worth of noting that the calculated values $\delta_{\mathrm{A}}$ are almost independent of the tested model chemistries, using free energies, we obtain $\delta_{\mathrm{A}}$ of $0.31-0.32$ by all methods including M062X and MP2.

The respective 2-D projection for derivative 4 (Figure $4 \mathrm{~b}$ ) shows similar features with steeper barrier curves reflecting stronger electron donating ability of the $-\mathrm{NMe}_{2}$ group. The main difference from derivative $\mathbf{2}$ is that the barrier to rotation of the D substituent is higher than $\mathrm{B}^{\prime \prime}$ so that we cannot state now

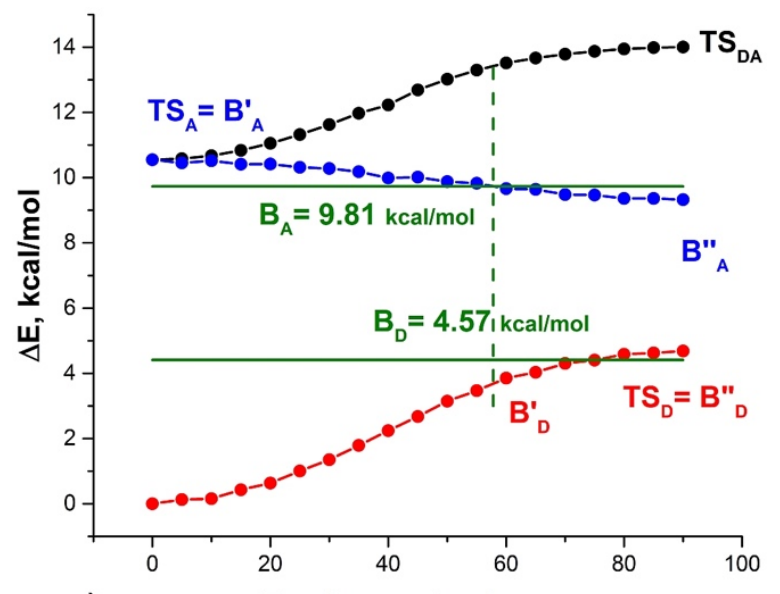

a) Torsion angle, degree

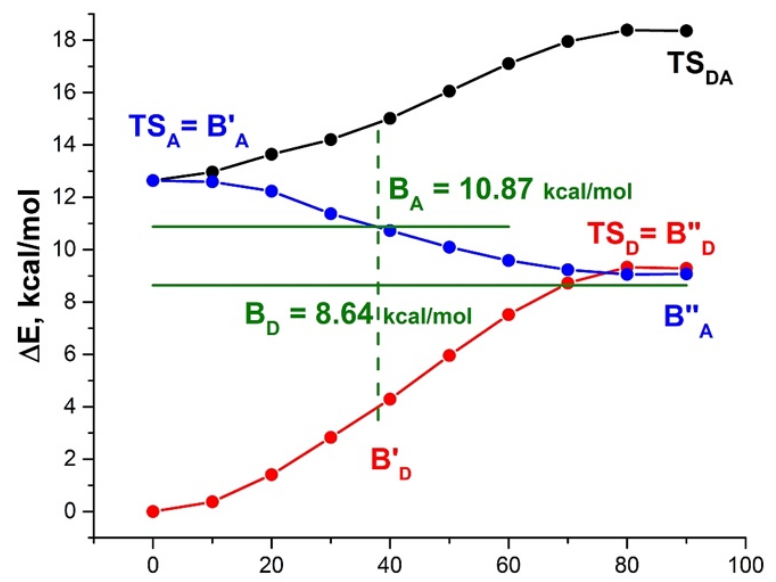

b)

Torsion angle, degree

Figure 4. 2-D projections of the surface maxima variation of $\Delta \mathrm{E}_{\text {tot }}$ (black curves), $\Delta \mathrm{E}_{\mathrm{A}}$ (blue curves) upon rotation of $\mathrm{D}$ substituents (red curves) from Figure 3: a) derivative 2, b) derivative 4. (B3LYP/aug-cc-pVDZ model chemistry).

that its rotation is independent of rotation of $A$ substituent in the range of the dihedral angles close to $T_{D}$. Therefore, $B_{D}$ is not equal to $T S_{D}$, as it is for derivative 2 and we need to introduce $\mathrm{B}^{\prime}{ }_{D}$ and $\mathrm{B}^{\prime \prime}{ }_{D}$ components and find their relative contributions in analogy to $B_{A}$. 
Using the same approach as described above, we determine $\delta_{\mathrm{A}}$ as $\mathrm{TS}_{\mathrm{D}} / \mathrm{TS}_{\mathrm{DA}}=0.51$ (from $\Delta \mathrm{E}$ calculations) and 0.52 (from $\Delta \mathrm{G}$ calculation), the latter value varies between 0.51 and 0.53 , except for MP2 $\left(\delta_{\mathrm{A}}=0.45\right)$. Using $\mathrm{B}^{\prime}{ }_{\mathrm{A}}=12.54$ and $\mathrm{B}^{\prime \prime}{ }_{\mathrm{A}} 7.55$ $\mathrm{kcal} / \mathrm{mol}$, we arrive to $B_{A}=10.87 \mathrm{kcal} / \mathrm{mol}$ (shown as the green horizontal line in Figure $4 \mathrm{~b}$ ). The maximal contribution of the polar structure $\mathrm{B}_{\mathrm{D}}{ }_{\mathrm{D}}$ can be determined by first applying $\delta_{\mathrm{A}}=0.51$ (green dashed vertical line in Figure $4 \mathrm{~b}$ ), since $\Delta \mathrm{E}_{D}$ is higher than $\mathrm{B}^{\prime \prime}{ }_{\mathrm{A}}$ only in the vicinity of $\mathrm{TS}_{\mathrm{D}}$ and $\delta_{\mathrm{D}}$ cannot be larger than $\delta_{\mathrm{A}}$. The contribution of the neutral free rotating form reaches unity at $\mathrm{TS}_{\mathrm{D}}$ and, therefore, $0.51<\delta_{D}<1$. Defining $\delta_{\mathrm{D}}$ as $\mathrm{TS}_{\mathrm{A}} / \mathrm{TS}_{\mathrm{DA}}$, we obtain $\delta_{D}=0.59^{\ddagger}$ and $B_{D}=0.59 B^{\prime}{ }_{D}+0.41 B^{\prime \prime}{ }_{D}=8.64 \mathrm{kcal} / \mathrm{mol}$. Using the free energy calculation results, $B_{A}=10.27 \mathrm{kcal} / \mathrm{mol}$ at $208 \mathrm{~K}$ and $\mathrm{B}_{\mathrm{D}}=7.52 \mathrm{kcal} / \mathrm{mol}$ at $133 \mathrm{~K}$ (B3LYP/aug-cc-pVDZ model chemistry). A larger basis set improves the both calculated barriers: $B_{A}=10.36 \mathrm{kcal} / \mathrm{mol}$ at $208 \mathrm{~K}$ and $\mathrm{B}_{\mathrm{D}}=7.83$ $\mathrm{kcal} / \mathrm{mol}$ at $133 \mathrm{~K}(\mathrm{~B} 3 \mathrm{LYP} / 6-311++\mathrm{G}(2 \mathrm{df}, 2 \mathrm{p})$ model chemistry), but the values of $\delta$ are again practically independent of the calculation levels.

The above scheme is applicable also for derivative 2, although the $\mathrm{TS}_{\mathrm{D}}$ for this compound is lower than $\mathrm{TS}_{\mathrm{A}}$ at any dihedral angle of the -OMe group as shown in Figure $4 \mathrm{a}$. In this case, according to this scheme, the calculated $\mathrm{TS}_{\mathrm{D}}=4.68$ and $\mathrm{B}_{\mathrm{D}}=4.57$ $\mathrm{kcal} / \mathrm{mol}, \delta_{D}=0.69$. For derivative 1 involving a weakest electron donor, $\mathrm{TS}_{\mathrm{D}}=0.07$ and $\mathrm{B}_{\mathrm{D}}=0.07 \mathrm{kcal} / \mathrm{mol}, \delta_{D}=0.99$.

The proposed barriers estimation scheme eliminates the necessity of computing and analyzing full surfaces and requires only optimization of three transition states corresponding to two conjugated rotors. Using $\delta_{\mathrm{A}}$ and $\delta_{\mathrm{D}}$ also takes into account the degree of curvature of variations of $\Delta \mathrm{E}_{\mathrm{A}}$ and $\Delta \mathrm{E}_{\mathrm{D}}$ (see Figure $3 S$ in ESI). It works well for derivatives 1, 2, 4, 5 with $\mathrm{TS}_{D}<\mathrm{TS}_{\mathrm{A}}$. For derivatives 6 and $\mathbf{7}$ with $\mathrm{TS}_{\mathrm{A}}<\mathrm{TS}_{\mathrm{D}}$, it works equally well, requiring just replacing the indices $A$ for $D$ in the expression (1). The general equation (2) used for calculating the higher barriers $\mathrm{TS}_{\mathrm{A}(\mathrm{D})}$ and (3) for the lower barriers $\mathrm{TS}_{\mathrm{D}(\mathrm{A})}$ are:

$\delta_{A(D)}=T_{D(A)} / T S_{D A}, B_{A(D)}=\delta_{A(D)} B_{A(D)}^{\prime}+\left(1-\delta_{A(D)}\right) B^{\prime \prime}{ }_{A(D)}$

$\delta_{D(A)}=B_{A(D)} / T S_{D A}, B_{D(A)}=\delta_{D(A)} B^{\prime}{ }_{D(A)}+\left(1-\delta_{D(A)} B^{\prime \prime}{ }_{D(A)}\right.$

The largest $\delta=0.66$, corresponding to the largest contribution of the polar conjugated mesomeric form, was found for derivative 7. For this derivative, $\mathrm{B}_{\mathrm{D}}{ }_{\mathrm{D}}=18.28$ and $\mathrm{B}^{\prime \prime}{ }_{\mathrm{D}}=10.05 \mathrm{kcal} /$ mol (from free energies at RT) affording $B_{D}=\Delta G^{\neq}=14.96$ $\mathrm{kcal} / \mathrm{mol}$, in excellent agreement with the experiment.

Derivative 3, however, is an exception. Since calculated using B3LYP and APFD functionals $\mathrm{B}^{\prime}{ }_{\mathrm{A}} \approx \mathrm{B}^{\prime}{ }_{\mathrm{D}}$ and $\mathrm{B}^{\prime \prime}{ }_{\mathrm{A}} \approx \mathrm{B}_{\mathrm{D}} \approx \mathrm{B}^{\prime \prime}{ }_{\mathrm{D}}$ (Table $6 \mathrm{~S}, \mathrm{ESI})$ selecting the lower barrier is hardly possible and we apply no correction and use the one-state approximation. This case will be discussed in detail in the next section.

Although this approach should be valid for estimating the barriers using total energies, ZPE-corrected energies and free energies, we find that using free energies provides the best fit with the D-NMR results (Figure 5). The barriers calculated using B3LYP and APFD functionals are very similar and gave MADs of $0.28(6-311+G 2 d, p), 0.26$ (aug-cc-pVDZ) and $0.19 \mathrm{kcal} / \mathrm{mol}(6-$ $311++G(2 d f, 2 p)$. M062X functional afforded MAD of 0.63 $\mathrm{kcal} / \mathrm{mol}$. For more details see Figures $4 \mathrm{~S}$ and $5 \mathrm{~S}$, ESI.

\section{Scope and limitations of three-state approximation}

Actually, derivatives $\mathbf{2}-\mathbf{7}$ involve more than two electronically interacting rotating groups: three for derivative 2 (Me-O, MeO-

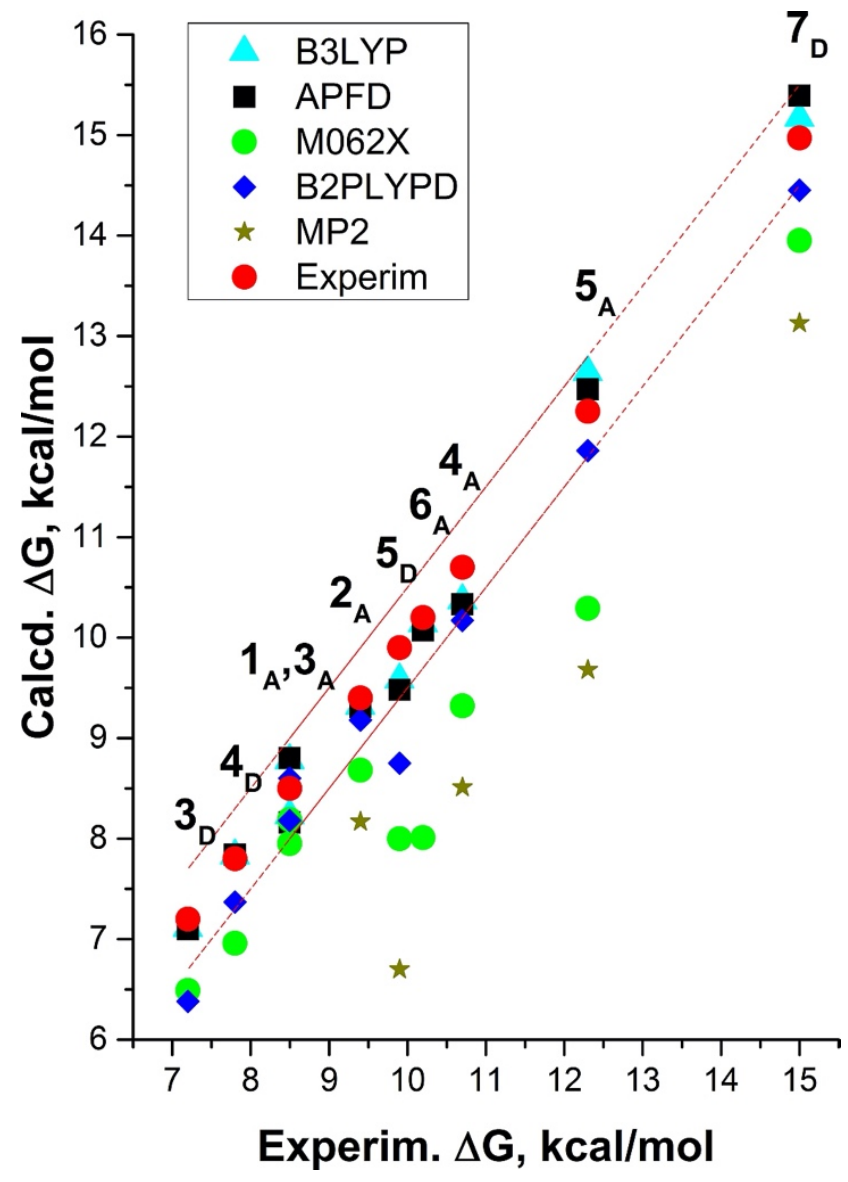

Figure 5. Calculated $\left(6-311++G(2 d f, 2 p)\right.$ basis set) $\Delta G_{A(D)}^{*}=B_{A(D)} \neq T S_{A D}$ (three-state approximation) vs. experimental $\Delta \mathrm{G}^{\neq}{ }_{\mathrm{A}(\mathrm{D})}$ (red line) for derivatives $\mathbf{1}$ - $\mathbf{7}$.

$\mathrm{C}$ and $\mathrm{C}-\mathrm{C}(\mathrm{O})$ ), five for 3 (two $\mathrm{Me}-\mathrm{N}, \mathrm{Me}_{2} \mathrm{~N}-\mathrm{C}, \mathrm{Me}-\mathrm{C}(\mathrm{O})$ and $\mathrm{MeCO}-\mathrm{C})$, etc. Is it possible to neglect their influence and consider only three transition states for two rotors? The case of derivative $\mathbf{3}$ is instructive and deserves a more detailed analysis. The experimental barrier to rotation of the $-\mathrm{C}(\mathrm{O}) \mathrm{CH}_{3}$ group in 3 is $8.5 \mathrm{kcal} / \mathrm{mol}$ at $\mathrm{T}_{\mathrm{c}}=181 \mathrm{~K}$, lower than the $-\mathrm{C}(\mathrm{O}) \mathrm{H}$ barriers determined for 2 and $4(9.4$ and $10.7 \mathrm{kcal} / \mathrm{mol}$, respectively, Table 1). As already mentioned, this molecule involves five rotating groups, of which two $\mathrm{Me}-\mathrm{N}$ and $\mathrm{Me}-\mathrm{C}(\mathrm{O})$ possess relatively low barriers to rotation of the Me group. Neglecting the influence of Me-N rotation is justified, since the NMR experiments showed that $\mathrm{N}, \mathrm{N}$-dimethyl-4-nitrosoaniline (5) and its $p$-mono-methylamino analog have practically the same barriers to rotation of the $-\mathrm{N}=\mathrm{O}$ group (see the discussion $\mathrm{in}^{32}$ and references therein). The weak, if any, effect of replacing the Me- group by hydrogen at the amino group can be rationalized by the insignificant interaction of the weak electron donating Me group with the strong electron donating amino group (D->Dbridge-A vs. D-bridge-A). At the same time, the difference between the experimental barriers of the acetyl group in $\mathbf{3}$ and the carbonyl group in $\mathbf{4}$, the molecules sharing the same bridge 
and the D group, is relatively large: $2.2 \mathrm{kcal} / \mathrm{mol}$. This strong effect can be rationalized by the stronger interaction of the Me group with the accepting carbonyl group weakening the accepting ability of the acetyl group (D->A-bridge-D vs. Abridge-D).

Calculations of the barriers for derivative 3 were carried out using B3LYP and APFD functionals $(6-311++G(2 d f, 2 p)$ basis set) in toluene, the frequency at $181 \mathrm{~K}$ for $\mathrm{TS}_{\mathrm{A}}$ and $133 \mathrm{~K}$ for $\mathrm{TS}_{\mathrm{D}}$ providing practically the same $\mathrm{TS}_{\mathrm{A}}$ and $\mathrm{TS}_{\mathrm{D}}$ at the coalescence temperature of the acetyl group signal (181K). The differences between $\mathrm{TS}_{\mathrm{A}}$ and $\mathrm{TS}_{\mathrm{D}}$ amount to $0.07 \mathrm{kcal} / \mathrm{mol}$ (B3LYP) and 0.03 $\mathrm{kcal} / \mathrm{mol}$ (APFD), the three-state approximation cannot formally be used and the calculated $B_{A}=T S_{A}$ are $8.23 \mathrm{kcal} / \mathrm{mol}$ (B3LYP) and $8.16 \mathrm{kcal} / \mathrm{mol}$ (APFD) were accepted (Table 6S, ESI). A larger difference between $T_{A}$ and $T S_{D}$ resulted from calculations of the barrier for the $\mathrm{Me}_{2} \mathrm{~N}$ - group at $133 \mathrm{~K}$ and using the threestate approximation scheme provided $\mathrm{B}_{\mathrm{D}}=7.1$ by both functionals (Table 10S, ESI).

The question of what difference between $\mathrm{TS}_{A}$ and $\mathrm{TS}_{\mathrm{D}}$ is meaningful for selecting between the one- and three-state approximation persists as calculations on different model chemistries produce different results. The answer may be obtained from calculating the respective surface and analyzing the areas where $\mathrm{TS}_{\mathrm{A}}$ and $\mathrm{TS}_{\mathrm{D}}$ overlap. However, the confusing results may stem from the neglect of the low barriers such as the barrier of the Me- groups in the $\mathrm{Me}-\mathrm{C}(\mathrm{O})$ group. $\mathrm{A}$ straightforward way to solve the problem with derivative $\mathbf{3}$ is to consider this molecule as a molecule involving three rotors. We have successfully tested the $m$-state approximation for derivatives IDX, $n=1,2$ (Scheme 1 ) and will report the results elsewhere. However, the number of states ' $m$ ' to be considered rapidly increases with the increasing number of rotors in the molecule making such calculations quite expensive. Therefore, we applied the three-state approximation after fixing the Me group in its rotational transition state $\mathrm{TS}_{\mathrm{Me}}$ to obtain the initial models for transition states $\mathrm{TS}_{\mathrm{D}}, \mathrm{TS}_{\mathrm{A}}$ and $\mathrm{TS}_{\mathrm{DA}}$ and re-optimizing each of the state to saddle points of orders 2 and 3 . The $\mathrm{TS}_{A}$

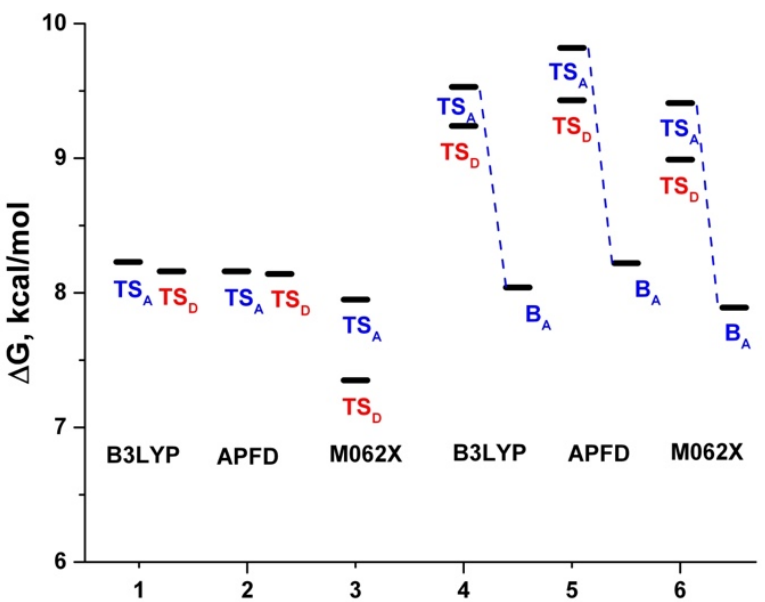

Figure 6. $1-3$ : Barriers to rotation $\mathrm{TS}_{\mathrm{A}}=\mathrm{B}_{\mathrm{A}}$ of the acetyl group Me-COcalculated for 3 using the one-state approximation; $4-6$ : barriers to rotation $\mathrm{BA}$ calculated for $\mathbf{3}$, involving the Me group of $\mathrm{Me}-(\mathrm{CO})$ in rotational transition state $\mathrm{TS}_{\mathrm{Me}}$, using the three-state approximation. increased by $1.3-1.7 \mathrm{kcal} / \mathrm{mol}$ and, applying the three-state approximation, we obtained the barriers $B_{A}$ practically the same as the uncorrected values $B_{A}=T S_{A}$ produced by the one-state approximation (Figure 6) (Table 8S, ESI). We conclude that the three-state approximation is not very sensitive to rotation within the substituents when the barriers are relatively low, probably as a result of error cancellations.

Since we assumed that coefficients $\delta$ and $(1-\delta)$ estimate the contributions of the polar and the neutral mesomeric forms into the average conformation of the push-pull derivatives involving the rotating $D$ and $A$ substituents, these coefficients can be useful for estimating dipole moments of such molecules as well. The experimental dipole moments were determined at room temperature above the coalescence temperatures of derivatives 1, 2, 4 and 5, i.e., under conditions when both $D$ and A substituents are rotating. Indeed, we find that the dipole moments calculated (B3LYP/6-311++G(2df,2p) in toluene using a rough approximation neglecting contribution of $D$ substituents: $\mu=\mu_{\mathrm{GS}} \delta_{\mathrm{A}}+\mu_{\mathrm{TSDA}}\left(1-\delta_{\mathrm{A}}\right)$. provides good fit with the experimental values (Table 2 ).

Calculations of dipole moments using the three-state approximation impose stricter requirements on the basis sets. This issue will be discussed in detail elsewhere.

Table 2. Dipole moments (in D) calculated for the GS $\left(\mu_{1 s}\right)$ and using three-state approximation $\left(\mu_{3 s}\right), B 3 L Y P / 6-311++G(2 d f, 2 p)$, in toluene and experimental dipole moments in benzene at $25^{\circ} \mathrm{C}$

\begin{tabular}{|c|c|c|c|c|}
\hline Compd & $\mu_{1 \mathrm{~s}}$ & $\mu_{3 S}$ & $\mu_{\text {exper }}$ & Ref. \\
\hline 1 & 4.77 & 3.77 & 3.33 & 33, p. 286 \\
\hline 2 & 5.56 & 4.06 & 3.88 & -“- p. 287 \\
\hline 4 & 8.11 & 5.76 & 5.58 & -“-p. 331 \\
\hline 5 & 9.92 & 6.75 & 6.9 & -“- p. 294 \\
\hline
\end{tabular}

\section{Conclusions}

Calculations of barriers to hindered rotation that stem from charge transfer interaction between electron donating and electron accepting substituents via the conjugating bridge (D bridge - A) necessitate consideration of at least three transition states: $\mathrm{TS}_{\mathrm{D}}, \mathrm{TS}_{\mathrm{A}}$ and $\mathrm{TS}_{\mathrm{DA}}$, especially when the barriers exceed $9.5 \mathrm{kcal} / \mathrm{mol}$. Using the three-state approximation enables predicting the barriers to rotation and electronic structures of yet unknown molecular systems involving strong electron donors and acceptors. The degree of intramolecular charge transfer can be evaluated by using $\delta$ and (1- $\delta$ ) coefficients, which relevance is corroborated by the reasonable prediction of the dipole moments of push-pull derivatives.

Although we found that using M062X functional can give good results for 1,4-substituted benzene derivatives using the onestate approximation, it fails in other cases. The failures can stem from the special parametrization of this functional. ${ }^{18}$ Both B3LYP and APFD functionals gave very good fit for derivatives involving both moderate and large degree of charge transfer 
using the three-state approximation. Using aug-cc-pVDZ basis set with these functionals can be recommended for predicting the barriers for rotation of large push-pull conjugated systems.

\section{Conflicts of interest}

There are no conflicts to declare.

\section{Acknowledgements}

This work was supported by the computing facilities of CRCMM, 'Centre Régional de Compétences en Modélisation Moléculaire de Marseille'.

\section{Notes and references}

$¥$ Note that if $\delta_{\mathrm{A}}$ can be associated with $\delta^{\prime}$ (Scheme 1$),\left(1-\delta_{D}\right)$ is the analog of $\delta^{\prime \prime}$ when $\mathrm{TS}_{\mathrm{D}}$ is the lower barrier; When $\mathrm{TS}_{\mathrm{A}}$ is the lower barrier, $\delta_{\mathrm{D}}$ is the analog of $\delta^{\prime \prime}$ and $\left(1-\delta_{\mathrm{A}}\right)$ corresponds to $\delta^{\prime}$.

1 R. Misra and S. P. Bhattacharyya, Intramolecular Charge Transfer; Wiley-VCH: 2018; pp 243.

2 D. Casarini, L. Lunazzi and A. Mazzanti, Eur. J. Org. Chem., 201.

3 M. Oki, Applications of Dynamic NMR Spectroscopy to Organic Chemistry Vol. 4 of Methods in Stereochemical Analysis, Deerfield Beach, Basel 1985.; VCH Verlagsges. Weinheim: 1985; pp 423.

4 H. Kessler, Angew. Chem. Int. Ed. Engl., 1970, 9, 219. 0, 2035.

$5 \mathrm{~J}$. B. Foresman and $\mathbb{E}$. Frisch, Exploring Chemistry with Electronic Structure Methods, 3rd ed.; Gaussian, Inc.: Wallingford, CT: 2015; p. 255.

6 E. Kleinpeter, Z.Chem., 1989, 29, 196.

7 A. Haloui and Y. Arfaoui, J. Mol. Struct. THEOCHEM, 2010, 950, 13 .

8 A. Haloui and E. Haloui, J. Phys. Org. Chem., 2014, 27, 430.

9 I. Alkorta, C. Wentrup and J. Elguero, J. Mol. Struct. THEOCHEM, 2002, 585, 27.

10 C. Wentrup, R. Koch and E. Kleinpeter, Eur. J. Org. Chem., 2016, 4985.

11 H. Schwartz, R. Mazor, V. Khodorkovsky, L. Shapiro, J. T. Klug, E. Kovalev, G. Meshulam, G. Berkovic, Z. Kotler and S. Efrima, J. Phys. Chem. B, 2001, 105, 5914.

12 G. Meshulam, G. Berkovic, Z. Kotler, A. Ben-Asuly, R. Mazor, L. Shapiro and V. Khodorkovsky, Synthetic Metals, 2000, 115, 219.

13 L. Bekere, N. Larina, V. Lokshin, A. Ellern, M. Sigalov and V. Khodorkovsky, New J. Chem., 2016, 40, 6554.

14 V. Lokshin, L. Bekere and V. Khodorkovsky, Dyes and Pigments, 2017, 145, 570.

15 Gaussian 16, Revision A.02, M. J. Frisch, G. W. Trucks, H. B. Schlegel, G. E. Scuseria, M. A. Robb, J. R. Cheeseman, G. Scalmani, V. Barone, G. A. Petersson, H. Nakatsuji, X. Li, M. Caricato, A. V. Marenich, J. Bloino, B. G. Janesko, R. Gomperts, B. Mennucci, H. P. Hratchian, J. V. Ortiz, A. F. Izmaylov, J. L. Sonnenberg, D. Williams-Young, F. Ding, F. Lipparini, F. Egidi, J. Goings, B. Peng, A. Petrone, T. Henderson, D. Ranasinghe, V. G. Zakrzewski, J. Gao, N. Rega, G. Zheng, W. Liang, M. Hada, M. Ehara, K. Toyota, R. Fukuda, J. Hasegawa, M. Ishida, T. Nakajima, Y. Honda, O. Kitao, H. Nakai, T. Vreven, K. Throssell, J. A. Montgomery, Jr., J. E. Peralta, F. Ogliaro, M. J. Bearpark, J. J. Heyd, E. N. Brothers, K. N. Kudin, V. N. Staroverov, T. A. Keith, R. Kobayashi, J. Normand, K. Raghavachari, A. P. Rendell, J. C. Burant, S. S. Iyengar, J. Tomasi, M. Cossi, J. M. Millam, M. Klene, C. Adamo, R. Cammi, J. W. Ochterski, R. L.
Martin, K. Morokuma, O. Farkas, J. B. Foresman, and D. J. Fox, Gaussian, Inc., Wallingford CT, 2016.

16 A. D. Becke, J. Chem. Phys., 1993, 98, 5648.

17 A. Austin, G. A. Petersson, M. J. Frisch, F. J. Dobek, G. Scalmani and K. Throssell, J. Chem. Theory Comput., 2012, 8, 4989.

18 Y. Zhao and D. G. Truhlar, Theor. Chem. Acc., 2008, 120, 215.

19 T. Schwabe and S. Grimme, Phys. Chem. Chem. Phys., 2007, 9, 3397.

20 V. Khodorkovsky, R. A. Mazor and A. Ellern, Acta Crystallogr. C, 1996, 52, 2878.

21 J. Dabrowski and L. J. Kozerski, Org. Magn. Res., 1972, 4, 137.

22 M. L. Blanchard, A. Chevallier and G. J. Martin, Tetrahedron Lett., 1967, 8, 5057.

23 T. B. Grindley, A. R. Katritzky and R. D. Topsom, J. Chem. Soc., Perkin Trans. 2, 1975, 443-449.

24 R. E. Klinck, D. H. Marr and J. B. Stothers, Chem. Commun., 1967, 409.

25 P. J. Q. English, A. R. Katritzky, T. T. Tidwell and R. D. Topsom, J. Am. Chem. Soc., 1968, 90, 1767.

26 R. E. Klinck and J. B. Stothers, Canad. J. Chem., 1976, 54, 3267.

27 Y. Iwasaki, R. Morisawa, S. Yokojima, H. Hasegawa, C. Roussel, N. Vanthuyne, E. Caytan and O. Kitagawa, Chemistry Eur. J., 2018, 24, 4453.

28 K. Traskovskis, A. Bundulis and I. Mihailovs, Phys Chem Chem Phys, 2017, 20, 404.

29 E. Masson, Org. Biomol. Chem., 2013, 11, 2859.

30 C. Tonnelé and F. Castet, Photochem Photobiol Sci, 2019, 18, 2759.

31 E. A. Skorupska, R. B. Nazarski, M. Ciechańska, A. Jóźwiak and A. Kłys, Tetrahedron, 2013, 69, 8147.

32 D. A. Fletcher, B. G. Gowenlock, K. G. Orrell, V. Šik, Mag. Res. Chem., 1995, 33, 561.

33 A. L. McClellan, Tables of Experimental Dipole Moments. W H Freeman \& Co, London, 1963, 713 pp. 